\title{
Assessment of Knowledge regarding Vitamin D among Medical Undergraduate Students
}

\author{
Pratibha Manandhar, ${ }^{1}$ Naresh Manandhar,' Sunil Kumar Joshi' \\ 'Community Medicine Department, Kathmandu Medical College, Duwakot, Bhaktapur, Nepal.
}

\section{ABSTRACT \\ Introduction}

It is estimated that one billion people in the world have vitamin D deficiency and observed as a public health problem. The main objective of this study is to assess and compare the Vitamin D knowledge among MBBS, BDS and BSc. Nursing students of Kathmandu Medical College, Duwakot (before and after educational training).

\section{Methods}

This was a cross sectional study carried out at Kathmandu Medical College, Duwakot among 1st year MBBS, BDS and B.Sc Nursing students. Data was collected from 2nd -15th February 2020. A structured self designed multiple choice questionnaire was used. A written pretest assessment regarding vitamin $\mathrm{D}$ knowledge followed by a written posttest assessment was taken after a lecture class on vitamin D. Ethical approval was obtained from Institutional Review Committee of Kathmandu Medical College (Ref. 2812201809). The census data of students were taken. The data was analyzed using SPSS software version 20.0

\section{Results}

Mean differences between the pretest and posttest scores showed an increment of vitamin $D$ knowledge among MBBS students $(t=22.155, p=0.000)$, BDS students $(t=16.46, p=0.000)$ and B.Sc. Nursing students $(t=18.615, \mathrm{p}=0.000)$.

\section{Conclusions}

Interactive lecture class showed moderate gain on knowledge regarding vitamin $\mathrm{D}$ among the under graduate students. Health education interventions can improve the knowledge and increases self-efficacy of future doctors and nurses about vitamin D.

Keywords: educational training; medical students; pretest; posttest; vitamin D knowledge.

\section{INTRODUCTION}

Vitamin D is a fat-soluble, sunshine hormone needed during infancy, adolescence, adulthood, and pregnancy as it is required for normal calcium absorption from the gut and bone growth. ${ }^{1,2}$ Sunlight is the best source of 
vitamin D and its presence in food is limited. ${ }^{3}$ Cutaneous synthesis of vitamin D is obtained by the conversion of 7-dehydrocholesterol to cholecalciferol by ultraviolet Sunlight. ${ }^{4}$ Multiple health problems like cardiovascular diseases including hypertension, type 1 diabetes mellitus, periodontal diseases are related to vitamin $\mathrm{D}$ deficiency or insufficiency. ${ }^{5}$ Poor knowledge level and inadequate awareness are the main risk factors for vitamin D deficiency among people. ${ }^{6}$ Providing health education and creating awareness regarding vitamin D to students will promote health and gain knowledge. ${ }^{7}$ As they are future health providers, it will help for progression of health promoting behaviors for themselves and the community. ${ }^{7}$ The main objective of this study is to assess and compare the knowledge of vitamin D among MBBS, BDS and BSc. Nursing students of Kathmandu Medical College, Duwakot (before and after educational training.)

\section{METHODS}

This is a descriptive cross sectional study conducted among first year students who were just enrolled on $23^{\text {rd }}$ batch of Bachelor of Medicine and Bachelor of Surgery (MBBS), 8th batch of Bachelor in Dental Surgery (BDS) and 15th batch of Bachelor of Science in Nursing (BSc. Nursing) at Kathmandu Medical College, Duwakot, Bhaktapur, Nepal. The study duration was from $2^{\text {nd }}$ February 2020 - $15^{\text {th }}$ February 2020. Students were enrolled by taking a census data using a structured questionnaire. Section A questionnaire consists of socio-demographic characteristics and Section B questionnaire is a self-designed, structured multiple-choice question (MCQ) for knowledge assessment regarding vitamin $\mathrm{D}$ (eg. ever heard the word vitamin $\mathrm{D}$, the main food source, the daily recommended dose, the average time required for Sun exposure to obtain vitamin $\mathrm{D}$, vitamin D deficiencyrelated diseases etc.). Fifteen minutes written pretest containing section $\mathrm{A}$ and section $\mathrm{B}$ questionnaire was taken followed by thirty minutes interactive lecture class on vitamin $\mathrm{D}$ as an educational training was delivered by the first author. A written 15 min posttest containing same section A and section B questionnaire was taken immediately after the educational training. Pretest and posttest vitamin D knowledge score of each participant was compared. Finally, the posttest total knowledge score of each participant was calculated and categorized as good, average and poor. Out of the total 51 scores, poor knowledge was defined as 0-11, average was 12-21 and good was $\geq 22$ respectively. Ethical approval was obtained from Institutional Review Committee of Kathmandu Medical College (Ref. 2812201809) and a written consent was signed by all participants. The data was analyzed using Statistical Package of Social Sciences (SPSS) software version 20.0. Statistical analysis was done by descriptive statistics with paired t-test and $p$ value $<0.05$ was taken as statistically significant.

\section{RESULTS}

Altogether 157 students were enrolled in this study. Among them 83 were MBBS, 39 were BDS and 35 were BSc. Nursing students. Among 83 MBBS students, 59 (71.1\%) were Nepalese. $57(68.7 \%)$ were boys and most of them were non-vegetarian. Similarly, among the BDS students, 34 (87.21\%) were nonvegetarian, $33(84.5 \%)$ were girls and all of them were Nepalese. Out of 35 B.Sc. Nursing students, all were girls, from Nepal and 30 $(85.7 \%)$ were non vegetarian. Fifty eight (69.9 $\%)$ MBBS students, $28(71.8 \%)$ BDS and 34 (97.1\%) Nursing students are of less than 20 yr of age. (Table.1). 


\begin{tabular}{|c|c|c|c|c|}
\hline SN & Variables & MBBS & BDS & Nursing \\
\hline \multirow{4}{*}{1} & Gender & & & \\
\hline & Boys & $57 \quad(68.7 \%)$ & $6 \quad(15.4 \%)$ & - \\
\hline & Girls & $26 \quad(31.3 \%)$ & $33 \quad(84.6 \%)$ & $35 \quad(100 \%)$ \\
\hline & Total & $83 \quad(100 \%)$ & $39 \quad(100 \%)$ & $35 \quad(100 \%)$ \\
\hline \multirow{5}{*}{2} & Citizens & & & \\
\hline & Nepali & $59 \quad(71.1 \%)$ & $39 \quad(100 \%)$ & $35 \quad(100 \%)$ \\
\hline & Indian & $23 \quad(27.7 \%)$ & - & - \\
\hline & Maldivian & $1 \quad(1.2 \%)$ & - & - \\
\hline & Total & $83 \quad(100 \%)$ & $39 \quad(100 \%)$ & $35 \quad(100 \%)$ \\
\hline \multirow{4}{*}{3} & Age groups & & & \\
\hline & $<20$ yrs & $58 \quad(69.9 \%)$ & $28 \quad(71.8 \%)$ & $34 \quad(97.1 \%)$ \\
\hline & 20- 25 yrs & $25 \quad(30.1 \%)$ & $11 \quad(28.2 \%)$ & $1 \quad(2.9 \%)$ \\
\hline & Total & $83(100 \%)$ & $39 \quad(100 \%)$ & $35 \quad(100 \%)$ \\
\hline \multirow{5}{*}{4} & Food Preference & & & \\
\hline & Non-Vegetarian & $60 \quad(72.3 \%)$ & $34 \quad(87.2 \%)$ & $30 \quad(85.7 \%)$ \\
\hline & Vegetarian & $16 \quad(19.3 \%)$ & $3 \quad(7.7 \%)$ & $3 \quad(8.6 \%)$ \\
\hline & Eggtarian & $7 \quad(8.4 \%)$ & $2 \quad(5.1 \%)$ & $2 \quad(5.7 \%)$ \\
\hline & Total & $83 \quad(100 \%)$ & $39 \quad(100 \%)$ & $35(100 \%)$ \\
\hline
\end{tabular}

Pretest and posttest mean knowledge of each student of MBBS, BDS and BSc. Nursing students were compared. In MBBS category, mean knowledge on vitamin $\mathrm{D}$ in pretest was $16.82(32.98 \%)$ and posttest was 32.61(63.94\%) ( $\mathrm{p}=0.000$ ) whereas in BDS category, mean knowledge was $17.28 \quad(33.78 \%)$ and 32.62 $(63.96 \%)$ respectively $(p=0.000)$. Finally, in BSc. Nursing category, mean pretest knowledge was $15.29(29.98 \%)$ and posttest was 32.03(62.28\%) $(\mathrm{p}=0.000)$. (Table. 2$)$.

Table 2. Pretest and Posttest knowledge score.

\section{Vitamin D mean Knowledge}

\begin{tabular}{|l|l|l|l|l|l|l|}
\hline & \multicolumn{2}{|c|}{ Pre test } & \multicolumn{2}{c|}{ Post test } & \multicolumn{2}{c|}{ Paired T test } \\
\hline Faculty & \multicolumn{1}{|c|}{ Mean } & \multicolumn{1}{c|}{$\%$} & \multicolumn{1}{c|}{ Mean } & $\%$ & t & \multicolumn{1}{c|}{ p value } \\
\hline MBBS & 16.82 & 32.98 & 32.61 & 63.94 & 22.155 & 0.000 \\
\hline BDS & 17.23 & 33.78 & 32.62 & 63.96 & 16.46 & 0.000 \\
\hline BSc. Nursing & 15.29 & 29.98 & 32.03 & 62.28 & 18.61 & 0.000 \\
\hline
\end{tabular}


While analyzing vitamin D knowledge assessment of mean score (maximum score 51) (difference between pretest and posttest) out of 83 MBBS students, 51(61.4\%) were good, 31(37.3\%) were average and only one $(1.2 \%)$ was in poor category. Similarly, out of 39 BDS students, $34(82.2 \%)$ were good, $4(10.3 \%)$ were average and only one $(2.6 \%)$ was in poor category. Whereas, out of 35 BSc. Nursing students, 28(80\%) were in good category and $7(20 \%)$ were in average category and none of them were in poor category. (Table. 3). showed that among 186 participants, 51.3\% showed good knowledge regarding Vitamin D and $48.7 \%$ showed poor knowledge. ${ }^{9}$ Whereas in our study, most of the students had scored good knowledge after post test (MBBS 61.4\%. BDS $82.2 \%$, BSc. Nursing 80\%). Probably this increment knowledge could be due to positive impact of vitamin D lecture class.

Conclusion: Findings obtained via this study depicted the prevailing trend of knowledge increment after lecture class among MBBS, BDS and BSc. Nursing students. This knowledge

\begin{tabular}{|c|c|c|c|c|c|}
\hline & Poor & & Average & Good & Total Students \\
\hline Faculty & No. $(\%)$ & No. & $(\%)$ & No. $(\%)$ & No. (\%) \\
\hline MBBS & $1 \quad(1.2)$ & 31 & $(37.3)$ & $51 \quad(61.4)$ & $83 \quad(100)$ \\
\hline BDS & $1 \quad(2.6)$ & 4 & $(10.3)$ & $34 \quad(82.2)$ & $39 \quad(100)$ \\
\hline BSc Nursing & - & 7 & (20) & $28 \quad(80)$ & $35 \quad(100)$ \\
\hline
\end{tabular}

\section{DISCUSSION}

This study evaluated pretest and posttest knowledge assessment regarding vitamin D before and after educational training. The pretest mean knowledge score among MBBS students was $32.99 \%$ and posttest was $63.94 \%$, among BDS students $33.78 \%$ and $63.96 \%$ respectively and among BSc. Nursing students 29.98\% and $62.28 \%$ respectively suggesting double increment of knowledge after educational training. The possible explanation could be that the participants gained knowledge after being educated on vitamin D. A study done by Harris $\mathrm{H}$ in Walden University found that among 108 participants, the average pretest score was $53.0 \%$ as compared to the posttest mean of $96.9 \%$ suggestive of knowledge gain after vitamin D education class. ${ }^{8}$ These findings highlighted that there is a definite role of educational intervention in knowledge increment.

A study done by Amri F Al et al in Saudi Arabia increment among these students will help for progression of health promoting behaviors for themselves and the community.

\section{ACKNOWLEDGEMENTS}

My sincere hearty thanks to $23^{\text {rd }}$ batch MBBS, $8^{\text {th }}$ BDS and 15th batch B.Sc. Nursing students for their kind participation in this study.

\section{Funding: None}

Conflict of Interest: None 


\section{REFERENCES}

1. Andiran N, Celik N, Akca $\mathrm{H}$, et al. Vitamin D Deficiency in Children and Adolescents. J Clin Res Pediatr Endocrinol. 2012; 4(1):25-29.

2. Holick MF. Vitamin D deficiency. N Engl J Med. 2007 Jul 19; 357(3):266-81.

3. Alshamsan FM, Bin-Abbas BS. Knowledge, awareness, attitudes and sources of vitamin D deficiency and sufficiency in Saudi children. Saudi Med J. 2016 May; 37(5): 579-83.

4. Bonevski B, Bryant J, Lambert S, Brozek I, Rock V. The ABC of Vitamin D: A qualitative study of the knowledge and attitudes regarding vitamin d deficiency amongst selected population groups. Nutrients 2013; 5: 915-27.

5. Anand N, Chandrasekaran SC, Rajput NS. Vitamin D and periodontal health: Current concepts. J Indian Soc Periodontol. May 2013; 17(3):302-8.
6. Peterlik M, Boonen S, Cross HS, Lamberg AC. Vitamin D and calcium insufficiency-related chronic diseases: an emerging world-wide public health problem. International Journal of Environmental Research and Public Health. Oct 2009;6(10):2585-07.

7. Safdar O, Baajlan O, Alamri A, Dahmash R, Alloush A, Ateeq R, et al. Assessment of knowledge and awareness of vitamin D among physicians and students of healthcare in Jeddah, Saudi Arabia. AMJ 2019; 12(5):143-53.

8. Nezhad AH, Holick MF. Vitamin D for health: A global perspective. Mayo Clin Proc 2013; 88(7):720-55.

9. Amri F Al, Gad A, Habib DA, Ibrahim AK. Knowledge, attitude and practice regarding Vitamin D among primary health care physicians in Riyadh city, Saudi Arabia, 2015. World Journal of Food Science and Technology 2017; 1 (2): 47-55.

Citation: Manandhar P, Manandhar N, Joshi S. Assessment of Knowledge regarding Vitamin D among Medical Undergraduate Students. JCMS Nepal. 2021; 17(3); 208-12. 